\title{
Euphausiid respiration model revamped: Latitudinal and seasonal shaping effects on krill respiration rates
}

\author{
Nelly Tremblay ${ }^{\mathrm{a}, *}$, Thorsten Werner ${ }^{\mathrm{a}}$, Kim Huenerlage ${ }^{\mathrm{a}}$, Friedrich Buchholz ${ }^{\mathrm{a}}$, \\ Doris Abele ${ }^{\mathrm{a}}$, Bettina Meyer ${ }^{\mathrm{b}}$, Thomas Brey ${ }^{\mathrm{a}}$ \\ a Functional Ecology, Alfred-Wegener-Institut Helmholtz-Zentrum für Polar- und Meeresforschung, Am Handelshafen, 27570 Bremerhaven, Germany \\ ${ }^{\mathrm{b}}$ Polar Biological Oceanography, Alfred-Wegener-Institut Helmholtz-Zentrum für Polar- und Meeresforschung, Am Handelshafen, 27570 Bremerhaven, \\ Germany
}

\section{A R T I C L E I N F O}

\section{Article history:}

Received 11 April 2014

Received in revised form 26 July 2014

Accepted 28 July 2014

Available online 28 August 2014

\section{Keywords:}

Euphausia superba

Euphausia pacifica

Meganyctiphanes norvegica

Artificial neural network

General additive model

Respiration data sets

\begin{abstract}
A B S T R A C T
Euphausiids constitute a major biomass component in shelf ecosystems and play a fundamental role in the rapid vertical transport of carbon from the ocean surface to the deeper layers during their daily vertical migration (DVM). DVM depth and migration patterns depend on oceanographic conditions with respect to temperature, light and oxygen availability at depth, factors that are highly dependent on season in most marine regions. Here we introduce a global krill respiration ANN (artificial neural network) model including the effect of latitude ( $L A T)$, the day of the year $(D o Y)$, and the number of daylight hours $(D L h)$, in addition to the basal variables that determine ectothermal oxygen consumption (temperature, body mass and depth). The newly implemented parameters link space and time in terms of season and photoperiod to krill respiration. The ANN model showed a better fit $\left(r^{2}=0.780\right)$ when $D L h$ and $L A T$ were included, indicating a decrease in respiration with increasing $L A T$ and decreasing $D L h$. We therefore propose $D L h$ as a potential variable to consider when building physiological models for both hemispheres. For single Euphausiid species investigated in a large range of $D L h$ and $D o Y$, we also tested the standard respiration rate for seasonality with Multiple Linear Regression (MLR) and General Additive model (GAM). GAM successfully integrated $D L h\left(r^{2}=0.563\right)$ and $\operatorname{DoY}\left(r^{2}=0.572\right)$ effects on respiration rates of the Antarctic krill, Euphausia superba, yielding the minimum metabolic activity in mid-June and the maximum at the end of December. We could not detect DLh or DoY effects in the North Pacific krill Euphausia pacifica, and our findings for the North Atlantic krill Meganyctiphanes norvegica remained inconclusive because of insufficient seasonal data coverage. We strongly encourage comparative respiration measurements of worldwide Euphausiid key species at different seasons to improve accuracy in ecosystem modeling.
\end{abstract}

(c) 2014 Elsevier B.V. All rights reserved.

\section{Introduction}

Knowledge of metabolic rates under different environmental conditions and from latitudinal and seasonally differing scenarios is central information in comparative modeling of trophic carbon transport and ecosystem energetic cycling. Euphausiids constitute a significant component in many marine ecosystems and often

Abbreviations: $\mathrm{O}_{2}$, oxygen; DVM, diel vertical migration; $L A T$, latitude; $L O N$, longitude; $D$, sampling water depth; $D o Y$, day of year (1-365); $D L h$, number of daylight hours; $T$, measurement temperature (K); $M$, body mass $(\mathrm{J}) ; R R$, specific respiration rate $\left(\mathrm{JJ}^{-1} \mathrm{day}^{-1}\right)$; MLR, multiple regression model; ANN, artificial neural network; GAM, general additive model.

* Corresponding author. Tel.: +49 4714831 1567; fax: +49 47148311149.

E-mail addresses: nellytremblay@gmail.com, nelly.tremblay@awi.de (N. Tremblay). several or even a single krill species connect primary production to apex predator trophic levels. Data on respiration rates of krill species have been collected since the 1960s as indicators for aerobic energy turnover. Recently Ikeda (2012) presented a stepwise multiple regression model (based on 39 sources of data sets composed of 24 species from various types of ecosystems) describing a significant dependence of krill respiration rates on body mass, habitat temperature, and water sampling depth. This first attempt to include water depth in a general Euphausiids respiration model indicated respiration rates to decline with water depth. The negative depth effect on krill metabolic rates was attributed to lower temperatures and diminishing oxygen concentrations at depth, affecting the Euphausiids when they migrate down at dusk (Enright, 1977). Further, Ikeda (2012) attributed the metabolic slowdown to a reduction of the energetic costs of swimming in the absence of visual predators in deep and dark oceanic layers. 


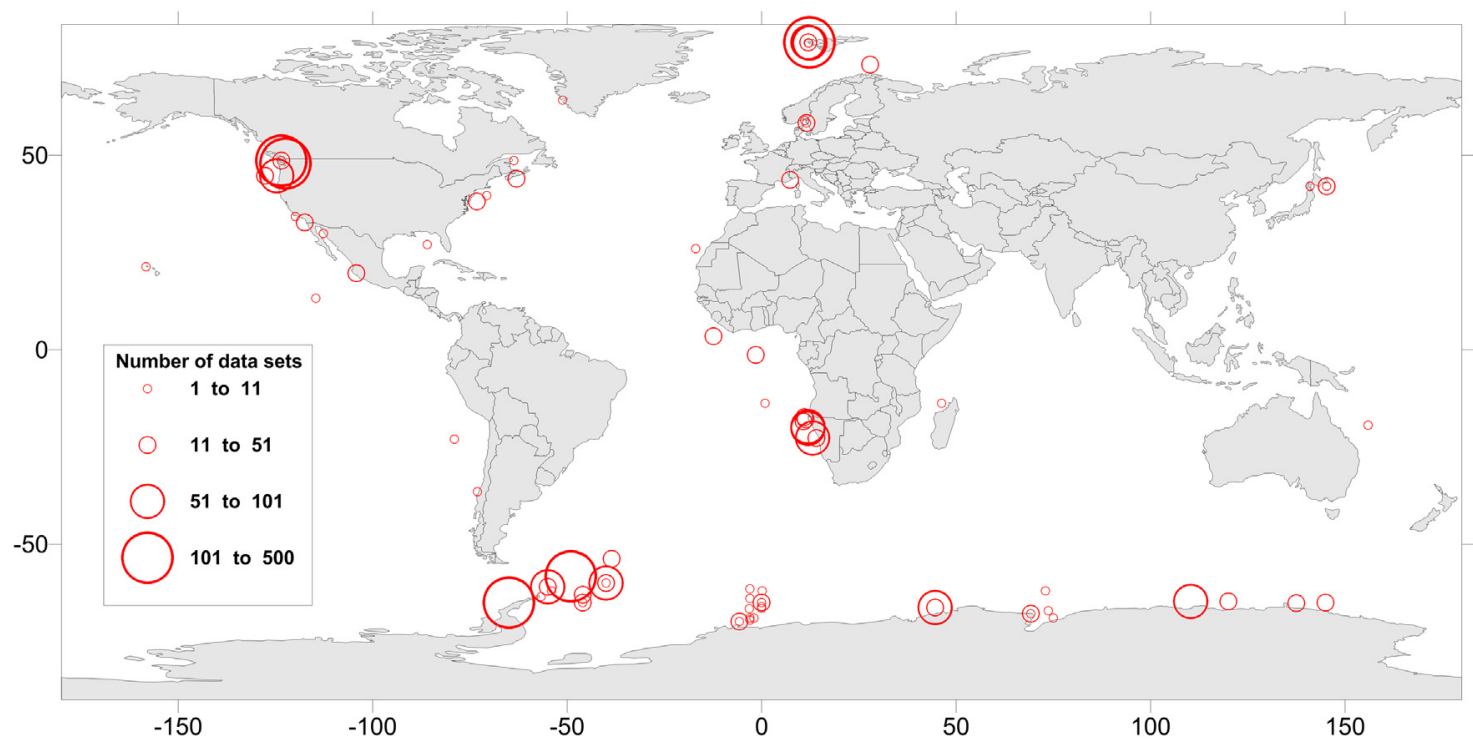

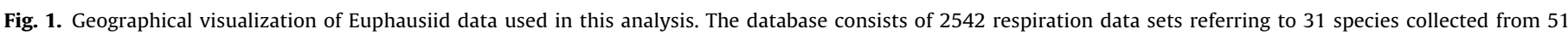
different sources (Tremblay et al., 2014).

Identification of "depth" as a factor modulating respiration rates raises the need to understand which environmental factors determine the vertical distribution range of krill species and the time span during which they remain in the deep water layers. Indeed, important differences in timing and depth range of diel vertical migration (DVM) among seasons or under different oceanographic regimes (upwelling/downwelling) have been reported for Euphausiid species from different areas (Gaten et al., 2008; Taki, 2008; Tremblay et al., 2010; Sato et al., 2013; Werner and Buchholz, 2013; Haraldsson and Siegel, 2014). Hence we presume that, next to water depth, other factors related to season and photoperiod will affect Euphausiid respiration on a global scale and most likely at the species level, too.

Here we analyze a global respiration data compilation comprising 2479 respiration data sets from 23 species that includes the factors "latitude", the "day of the year", and the "number of daylight hours" as proxies for season and photoperiod. We intend to establish a corresponding general Euphausiid respiration model and to analyze seasonal patterns of respiration within single Euphausiid species.

\section{Materials and methods}

\subsection{Initial data}

Following the same criteria of data acquisition and conditioning of Brey (2010), we searched the literature for Euphausiid respiration data and added recent unpublished data provided by several colleagues. The database consists of 2542 respiration data sets referring to 31 species collected from 51 different sources (see Tremblay et al., 2014 for complete data base in PANGAEA; Fig. 1). In this excel file, the information about the setting (closed, semi-closed, or intermittent flow) and the method of measurement (chem for chemical, micro-optodes, polar for polarographic electrodes, manom for manometer, or gas for gas analyser) are also summarized. For statistical reasons, some data sets were excluded from further analysis (refer to Section 2.2), leaving us with 2479 data sets relating to 23 species (Figs. 2 and 3). In some cases, the public domain software ImageJ (http://rsbweb.nih.gov/ij/) was used to extract respiration data from figures.
Each data set included the following parameters:

- Sampling site latitude $L A T$ and longitude $L O N$;

- Sampling water depth $D(\mathrm{~m}$; in 261 cases the reported depth was $<5 \mathrm{~m}$, these numbers were set to $D=5 \mathrm{~m}$ in order to avoid
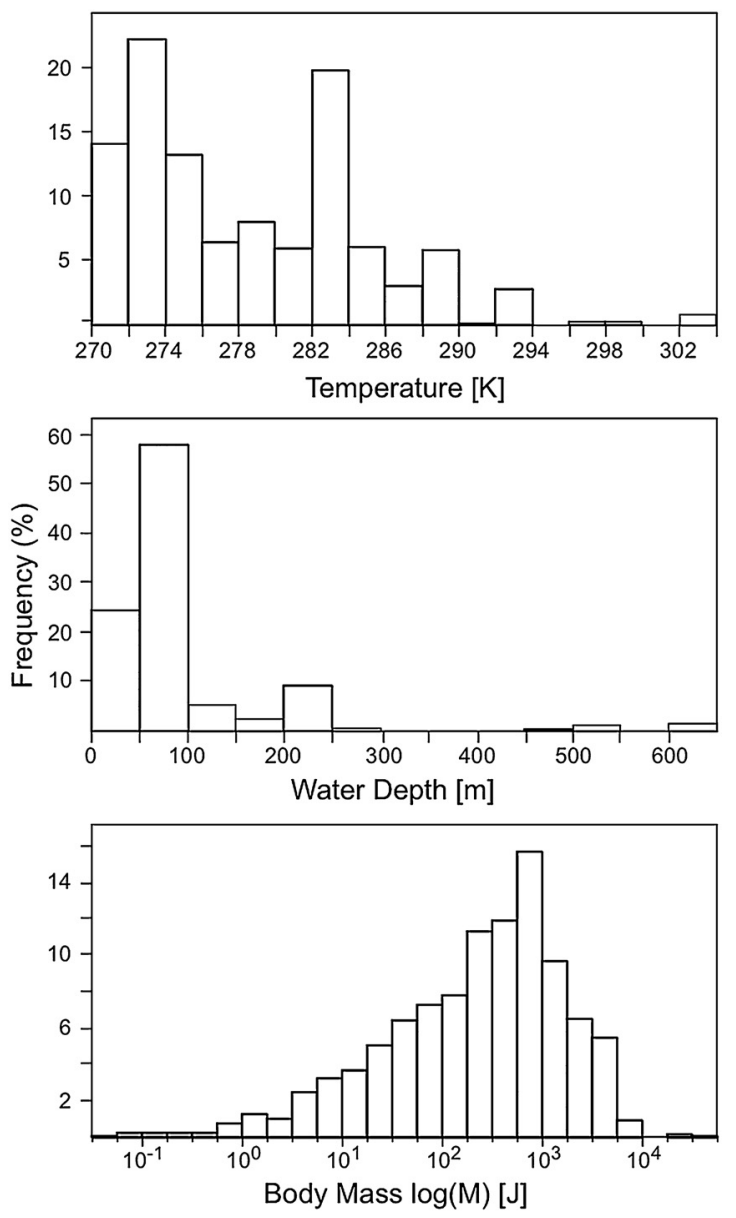

Fig. 2. Distribution of the 2479 respiration data sets with respect to water temperature (Kelvin), water depth (meters), and mean body mass (Joule). 


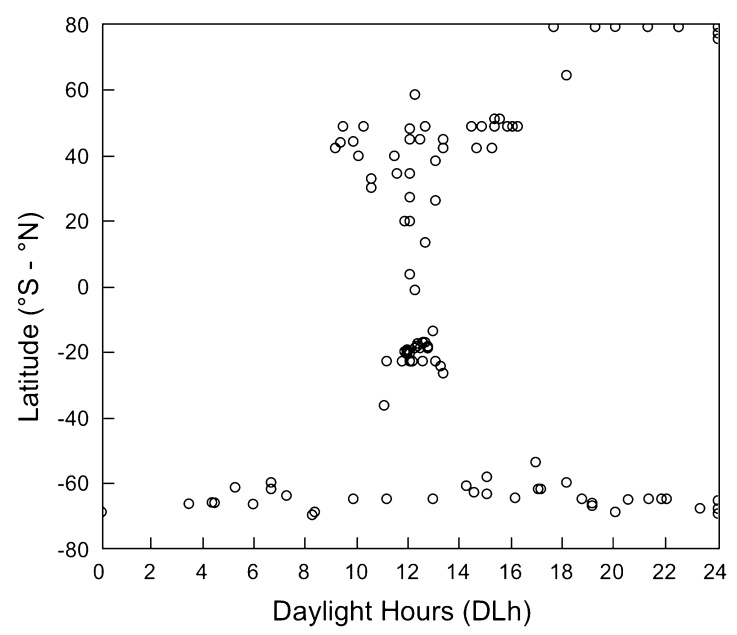

Fig. 3. Distribution of the 2479 respiration data sets with respect to daylight hours and geographical latitude.

disproportionate effects of very small depth values. In 311 cases with unknown sampling depth we set $D=80 \mathrm{~m}$, i.e. average depth in all data sets; in a further 14 cases where divers sampled the animals we set $D=5 \mathrm{~m})$;

- Day of the year DoY (day of year between 1 and 365); if a range of time was provided by the original source, we set DoY = midday of this range. When $D L h$ was set to $12 \mathrm{~h}$ (see below), DoY was set to 264 (which correspond to equinox of September 21th when the sun spends equal amount of time above and below the horizon at every location on the Earth, so night and day are about the same length), accordingly;

- Number of daylight hours DLh, calculated from LAT and $D o Y$ by the sunrise-sunset calculator (aa.usno.navy.mil/data/ docs/RS_OneDay.php). A few publications summarized data over a time period of more than one year; here we set $D L h$ to $12 \mathrm{~h}$;

- Measurement temperature $T(\mathrm{~K})$;

- Body mass $M(\mathrm{~J})$, converted from original body mass units using factors provided as for Brey (2010), and other sources when necessary;

- Specific respiration rate $R R\left(\mathrm{JJ}^{-1} \mathrm{day}^{-1}\right)$;

- Taxonomic information (species, genus, family).

\subsection{Data transformation E pre-analysis}

We decided to eliminate a priori four data sets with extreme water depth below $700 \mathrm{~m}$. Subsequently, specific respiration rate $R R$, body mass $M$, temperature $T$ and water depth $D$ were transformed by approximating linear relationships between independent variables and $R R$ according to theoretical considerations (e.g., Schmidt-Nielsen, 1984; Brown et al., 2004) and to empirical evidence (e.g. Seibel and Drazen, 2007; Brey, 2010) regarding the scaling of metabolic activity (see Brey, 2010 for a full discussion of this issue). These transformations $-\log (R R), \log (M), 1 / T$, $\log (D)$ - also facilitate a more even distribution of data and variance in the $[M, T, D]$ space. Multivariate outliers in the sample space $[\log (R R), \log (M), 1 / T, \log (D)]$ were identified by Hotelling's $T^{2}$ statistic (the square of the Mahalanobis distance; Barnett and Lewis, 1994; Prokhorov, 2001). Data sets with $T^{2}$ above the $97.5 \%$ percentile were excluded from further analysis, thus providing 2479 datasets referring to 23 species for statistical analysis (Figs. 2 and 3).

\subsection{General Euphausiid respiration model}

We applied fully factorial multiple regression models (MLR) as well as artificial neural network (ANN). MLRs may not appropriately
Input Layer Hidden Layer Output Layer

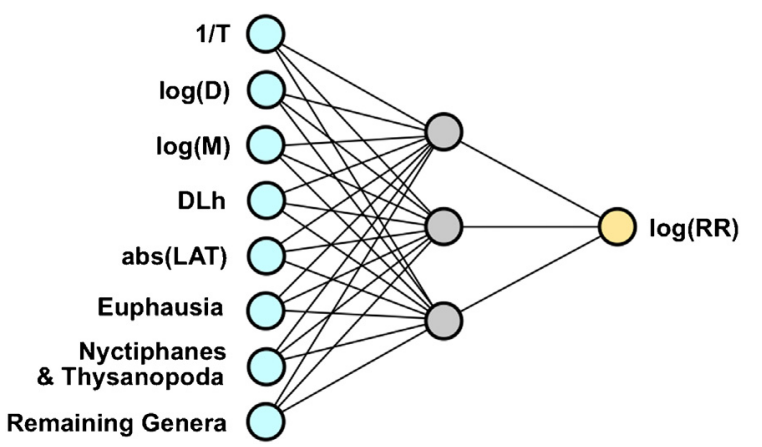

Fig. 4. Scheme of the artificial neural network (ANN) used to predict mass specific respiration rate $R R$ in Euphausiids from five continuous parameters (temperature, water depth, body mass, daylight hours, latitude) and three taxonomic categories.

describe the existing relationships despite linearizing transformations (see above) and are quite sensitive to intercorrelation between independent parameters (Draper and Smith, 1998). This is the reason why we applied ANN of the backpropagation type (Hagan et al., 1996). ANN "learned" the relationship between dependent and independent variables from training data and was tested for its generalization capacity by comparing prediction accuracy with training $(2 / 3)$ and test $(1 / 3)$ data as measured by the correlation between measured $R R_{\mathrm{m}}$ and predicted $R R_{\mathrm{ann}}$. An ensemble of five ANN, each trained on a bootstrapped random subsample, were pooled into a composite prediction model (see e.g., Boucher et al., 2010, Brey, 2010, 2012). Trial-runs with different sets of parameters indicated significant effects of $D o Y$, DLh and abs $(L A T)$. We preferred DLh over DoY for model building as both parameters are strongly correlated, but $D L h$ showed distinctly better performance. Taxonomic effects on $R R$ were evident at the genus level and were covered by three groups, (A) Euphausia, (B) Nyctiphanes \& Thysanopoda, (C) remaining genera (Meganyctiphanes, Nematoscelis, Thysanoessa). Accordingly, the MLR model had eight input parameters:

$$
\begin{aligned}
\log (R R)= & a+b_{1} \times \frac{1}{T}+b_{2} \times \log (D)+b_{3} \times \log (M)+b_{4} \times D L h+b_{5} \\
& \times \operatorname{abs}(L A T)+b_{6} \times \text { genus.A }+b_{7} \times \text { genus.C } \\
& + \text { interaction terms }
\end{aligned}
$$

The interaction terms parameters were adjusted to mean = zero in order to render the test for the main effects independent of the test for interactions ("centered polynomials"). The ANN consisted of 8 input nodes, three hidden nodes $(H)$, and one output node (Fig. 4). Trial runs indicated that three hidden nodes enabled the ANNs to learn properly without over-fitting. The network was parameterized as follows:

$\log (R R)=a_{0}+a_{1} \times H_{1}+a_{2} \times H_{2}+a_{3} \times H_{3}$

with

$H_{1}=\tan H\left(b_{0}+b_{1} \times 1 / T+b_{2} \times \log (D)+b_{3} \times \log (M)+\ldots b_{8} \times\right.$ genus.C $)$
$H_{2}=\tan H\left(c_{0}+c_{1} \times 1 / T+c_{2} \times \log (D)+c_{3} \times \log (M)+\ldots c_{8} \times\right.$ genus.C $)$
$H_{3}=\tan H\left(d_{0}+d_{1} \times 1 / T+d_{2} \times \log (D)+d_{3} \times \log (M)+\ldots d_{8} \times\right.$ genus.C $)$

Note that internally the input data were normalized (mean $=0$, S.D. =1) and that the network parameter values were adjusted accordingly. In order to see whether or not certain input parameters enhanced ANN's predictive power, we compared goodness of 
fit of differently sized ANN by means of ANOVA of the correlation coefficients $r^{2}$ of individual ANN test and training subsets.

\subsection{Seasonal respiration model for single Euphausiid species}

We selected those Euphausiid species with a considerable number of data sets distributed throughout the year, i.e. E. superba $(N=875)$, E. pacifica $(N=498)$ and M. norvegica $(N=132)$, for the analysis of seasonality in respiration rate. Other species showed great data sets, like Euphausia hanseni and Thysanoessa inermis, but their $R R$ measurements were not covering a large range of $D L h$ and $D o Y$. In a first step, we used a fully factorial MLR to describe the effects of $T, D$, and $M$ on $R R$ (see above).

$\log (R R)=a+b_{1} \times \frac{1}{T}+b_{2} \times \log (D)+b_{3} \times \log (M)$

+ interaction terms

Subsequently, we checked the residuals of the MLR for effects of $D o Y$ and $D L h$ on $R R$. We presumed that seasonal effects should manifest in a linear relationship between $D L h$ and $R R$, and in a corresponding sinusoidal relationship between $D o Y$ and $R R$. When those relationships were present, we used general additive models (GAM; Hastie and Tibshirani, 1990) to gain a better understanding of the seasonal patterns in respiration rate. We added a term $f(X)$ to the MLR above that described the relationship between $R R$ and $D L h$ or DoY, respectively. The GAM equation takes the general form (MLR interaction terms neglected for clarity in this display)

$\log (R R)=a_{1}+b_{1} \times \frac{1}{T}+b_{2} \times \log (D)+b_{3} \times \log (M)+b_{4} \times f(X)$

with $f(X)=a_{2}+b_{5} \times D L h$

or $f(X)=a_{2}+b_{6} \times \sin \left(2 \pi \times \frac{D o Y}{365-a_{3}}\right)$

\section{Results}

\subsection{General Euphausiid respiration model}

The MLR approach resulted in a very complex model with seven interaction terms $\left(r^{2}=0.680\right.$, all terms significant at $P<0.05$, model not shown). The corresponding ANN model showed a distinctly better fit $\left(r^{2}=0.780\right.$, Table 1 , Fig. 5; see spreadsheet "Respir EuphausiaceaANN.xlsx" downloadable at http://www.thomas-brey/science/virtualhandbook). ANN predictive performance increased significantly $(P<0.05)$ with increasing number of input parameters from three $(1 / T, \log (D), \log (M))$, to five (DLh and LAT included) to eight parameters (three genus terms included). The corresponding overall correlation between mean ANN prediction $R R_{\mathrm{ann}}$ and measured $R R_{\mathrm{m}}$ was $r^{2}=0.732,0.760$, and 0.780 , respectively. ANOVA further indicated that there were no differences in goodness of fit between test and training data sets. The contour plot in Fig. 6 demonstrates the effect of $D L h$ and of LAT on $R R_{\mathrm{ann}}$.

\subsection{Seasonal respiration model for single Euphausiid species}

\subsubsection{Euphausia superba}

Of the total 2479 Euphausiid data sets, 875 sets collected from 20 sources referred to E. superba (Fig. 7). We detected significant effects $(P<0.001)$ of $D L h$ and $D o Y$ on $R R$ (Fig. 8). The corresponding GAM (Table 2, Fig. 9) fitted the data distinctly better than the basic $\operatorname{MLR}\left(r^{2}=0.561\right.$ and 0.572 compared to 0.440$)$. Furthermore, depth $D$ did not contribute significantly to GAM predictive power and was therefore removed from the GAM equations. Fig. 9 indicates that the

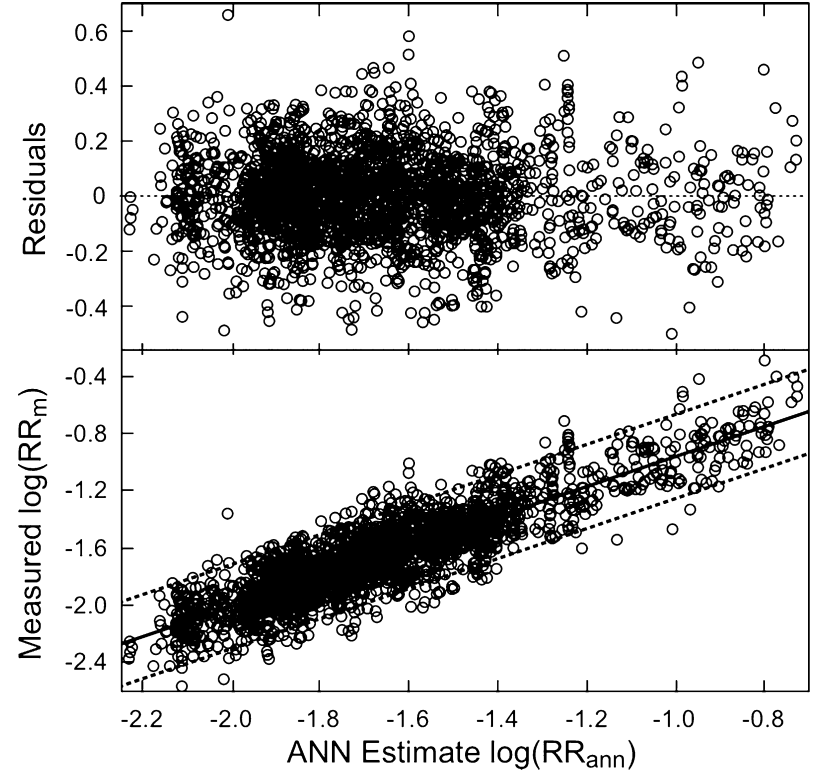

Fig. 5. Relationship between measured $R R_{\mathrm{m}}$ and ANN predicted $R R_{\mathrm{ann}}$ (below) and corresponding residual plot (above). See Table 1 for ANN model parameters. Stippled lines indicate $95 \%$ confidence range of predictions.

GAM term fully accounted for seasonal effects in $R R$. These effects were visualized in the contour plots in Fig. 10.

\subsubsection{Euphausia pacifica}

Of the 498 E. pacifica data sets (11 sources), one proved to be a consistent and distinct outlier in all models and was therefore excluded from further analysis. A fully factorial MLR analysis indicated significant effects of $T, D$, and $M$ on $R R$ as well as significant interactions between independent parameters (Table 3 ). There was a weak albeit significant sinusoidal relationship between the residuals of the MLR model and $\operatorname{DoY}\left(r^{2}=0.099, P<0.001\right)$, and a significant negative relationship between MLR residuals and $D L h$ $\left(r^{2}=0.137, P<0.001\right)$. We checked whether or not these relationships were artificially caused by one single source by means of excluding one source (with $\geq 10$ data sets) in turn from the residual analysis. The removal of the data published by Paranjape (1967) rendered the effects of $D o Y$ and $D L h$ insignificant (see Fig. 11). Hence

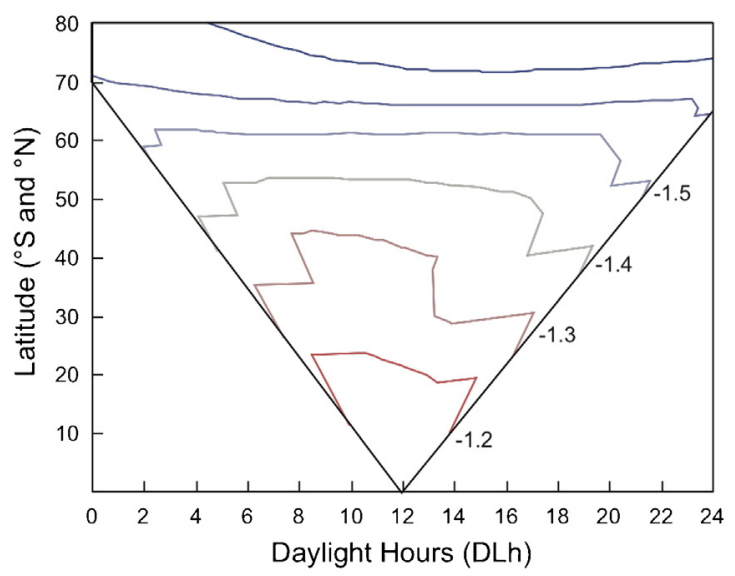

Fig. 6. Contour plot of $R R_{\text {ann }}$ predicted by the Euphausiid global respiration model (ANN) in the daylight hours DLh versus geographical latitude $L A T$ (north and south combined) space. DLh (as well as temperature) has been restricted to the range defined by geographical latitude. $R R_{\text {ann }}$ represents an average for body mass $0.1,1$, 10,100 , and $1000 \mathrm{~J}$. 
Table 1

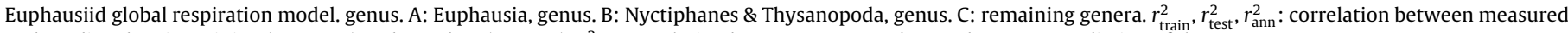
and predicted $R R$ in training $(N=1652)$ and test data $(N=826) ; r_{\text {ann }}^{2}$ : correlation between measured $R R$ and average prediction of the 5 ANN.

\begin{tabular}{|c|c|c|c|c|c|}
\hline \multicolumn{6}{|c|}{$\begin{array}{l}\log (R R)=a_{0}+a_{1} \times H_{1}+a_{2} \times H_{2}+a_{3} \times H_{3} \\
H_{1}=\tan H\left(b_{0}+b_{1} \times 1 / T+b_{2} \times \log (D)+b_{3} \times \log (M)+b_{4} \times D L h+b_{5} \times \operatorname{abs}(L A T)+b_{6} \times \text { genus.A }+b_{7} \times \text { genus. } \mathrm{B}+b_{8} \times \text { genus.C }\right) \\
H_{2}=\tan H\left(c_{0}+c_{1} \times 1 / T+c_{2} \times \log (D)+c_{3} \times \log (M)+\cdots c_{8} \times \text { genus.C }\right) \\
H_{3}=\tan H\left(d_{0}+d_{1} \times 1 / T+d_{2} \times \log (D)+d_{3} \times \log (M)+\cdots d_{8} \times \text { genus.C }\right)\end{array}$} \\
\hline & ANN1 & ANN2 & ANN3 & ANN4 & ANN5 \\
\hline$a_{0}=$ & -1.57197 & -1.51099 & -1.57066 & -1.64152 & -1.57065 \\
\hline$a_{1}=$ & 0.38857 & -0.21050 & 0.17855 & 0.38984 & -0.45136 \\
\hline$a_{2}=$ & -1.37002 & 0.38061 & -1.04624 & -0.47103 & 0.21583 \\
\hline$a_{3}=$ & -0.42258 & -0.19251 & 0.42496 & -1.01710 & -0.13727 \\
\hline$b_{0}=$ & -86.77930 & -194.63700 & -125.32500 & 33.20542 & -47.94690 \\
\hline$b_{1}=$ & $27,854.45$ & $57,230.88$ & $14,617.81$ & -9652.23 & $16,404.96$ \\
\hline$b_{2}=$ & 2.59290 & -0.12465 & -18.67730 & 2.36937 & -1.00100 \\
\hline$b_{3}=$ & 1.04828 & -0.49462 & 9.78115 & 0.15848 & 0.96578 \\
\hline$b_{4}=$ & -0.39650 & -0.02417 & 2.91508 & 0.19465 & -0.05447 \\
\hline$b_{5}=$ & -0.12200 & -0.14740 & 0.62981 & -0.07905 & -0.04532 \\
\hline$b_{6}=$ & -0.67903 & 0.75253 & -2.30198 & -3.28122 & 0.94072 \\
\hline$b_{7}=$ & -5.14599 & -0.37181 & 10.78545 & -0.46730 & -8.10712 \\
\hline$b_{8}=$ & 1.10279 & -1.23824 & 2.61575 & -2.55901 & -0.08386 \\
\hline$c_{0}=$ & -9.85757 & 2.09214 & -18.65530 & 35.89489 & 95.61789 \\
\hline$c_{1}=$ & 2298.77 & 2022.25 & 4485.97 & -4279.08 & $-12,644.40$ \\
\hline$c_{2}=$ & 0.82025 & -1.20340 & 0.13205 & -4.02182 & -0.43695 \\
\hline$c_{3}=$ & 0.36519 & -1.70364 & 0.68528 & -2.99786 & -5.58249 \\
\hline$c_{4}=$ & 0.00655 & -0.03503 & 0.11844 & 0.01114 & -1.05142 \\
\hline$c_{5}=$ & 0.00417 & -0.09131 & -0.00873 & -0.15218 & -0.29912 \\
\hline$c_{6}=$ & -0.25620 & 0.32410 & 0.57758 & -1.74016 & 5.36206 \\
\hline$c_{7}=$ & -0.41454 & 1.35509 & 0.36973 & 0.78609 & -9.49179 \\
\hline$c_{8}=$ & 0.32634 & -2.09254 & 0.73716 & -2.36783 & -5.76894 \\
\hline$d_{0}=$ & -92.03570 & -84.04100 & 32.26541 & -22.47070 & -110.62100 \\
\hline$d_{1}=$ & $28,677.77$ & $25,377.93$ & -7718.31 & 4158.86 & $-23,008.00$ \\
\hline$d_{2}=$ & -2.10915 & -0.20977 & 0.56556 & 2.17255 & 128.19910 \\
\hline$d_{3}=$ & 0.12831 & 3.43577 & 0.76223 & 1.27308 & 0.39724 \\
\hline$d_{4}=$ & -0.18612 & -0.35817 & 0.26208 & 0.07651 & 0.22187 \\
\hline$d_{5}=$ & -0.11352 & -0.22685 & -0.14171 & 0.02428 & 0.23487 \\
\hline$d_{6}=$ & 1.00402 & 4.27923 & -0.75113 & -0.72823 & -4.39197 \\
\hline$d_{7}=$ & 0.95282 & 5.95089 & -0.63204 & -1.12687 & -54.49430 \\
\hline$d_{8}=$ & -1.12534 & -3.35537 & -0.38697 & -0.34093 & 5.77147 \\
\hline$r_{\text {train }}^{2}=$ & 0.756 & 0.746 & 0.740 & 0.744 & 0.746 \\
\hline$r_{\text {test }}^{2}=$ & 0.751 & 0.746 & 0.741 & 0.740 & 0.760 \\
\hline$r_{\mathrm{ann}}^{2}=$ & 0.780 & & & & \\
\hline$N=$ & 2479 & & & & \\
\hline
\end{tabular}

the available data did not provide sufficient evidence for a clear effect of seasonality on $R R$ in E. pacifica.

\subsubsection{Meganyctiphanes norvegica}

A fully factorial MLR analysis of the $132 \mathrm{M}$. norvegica data sets (7 sources) indicated significant effects of $T, D$, and $M$ on $R R$
(Table 3). There was no significant sinusoidal relationship between the residuals of the MLR model and $\operatorname{DoY}(P=0.941)$. However, MLR residuals correlated negatively with $D L h$ (slope $=-0.012, r^{2}=0.186$, $P<0.001$, Fig. 12). As there were no data available for $D L h<8 \mathrm{~h}$, the seasonal pattern in $M$. norvegica metabolic activity remains inconclusive.

Table 2

Euphausia superba respiration models. Only significant terms $(P<0.05)$ are shown. Note the adjustment to mean $=$ zero for $\log (M), 1 / T$ and $D L h$.

\begin{tabular}{|c|c|c|}
\hline Multiple Linear Regression (MLR) & $\begin{array}{l}\text { General Additive Model (GAM) with } \\
\text { DLh }\end{array}$ & $\begin{array}{l}\text { General Additive Model (GAM) with } \\
\text { DoY }\end{array}$ \\
\hline $\begin{array}{l}\log (R R)=a+b_{1} \times 1 / T+b_{2} \times \log (D)+b_{3} \times \log (M)+b_{4} \\
\quad \times(1 / T-0.00366) \times \log (M-2.6409)+b_{5} \\
\quad \times(1 / T-0.00366) \times \log (D-1.4751)\end{array}$ & $\begin{array}{l}\log (R R)=a_{1}+b_{1} \times 1 / T+b_{2} \times \log (M) \\
+b_{3} \times(1 / T-0.00366) \times \log (M-2.6409) \\
+\mathrm{b}_{4} \times f(D L h)\end{array}$ & $\begin{array}{l}\log (R R)=a_{1}+b_{1} \times 1 / T+b_{2} \times \log (M) \\
+b_{3} \times(1 / T-0.00366) \times \log (M-2.6409) \\
+b_{4} \times f(D o Y)\end{array}$ \\
\hline $\begin{array}{l}a=14.4498 \\
b_{1}=-4301.6310 \\
b_{2}=-0.1298 \\
b_{3}=-0.1196 \\
b_{4}=-1105.8590 \\
b_{5}=2804.0944\end{array}$ & $\begin{array}{l}f(D L h)=a_{2}+b_{5} \times(D L h-14.1929) \\
a_{1}=14.9328 \\
a_{2}=257.2753 \\
b_{1}=-4501.6350 \\
b_{2}=-0.1688 \\
b_{3}=-835.8796 \\
b_{4}=0.00068 \\
b_{5}=33.4871\end{array}$ & $\begin{array}{l}f(D o Y)=a_{2}+b_{5} \times \sin \left(2 \pi \times\left(D o Y / 365-b_{6}\right)\right) \\
a_{1}=11.0246 \\
a_{2}=91.2073 \\
b_{1}=-3387.1049 \\
b_{2}=-0.1684 \\
b_{3}=-1300.6526 \\
b_{4}=-0.000084 \\
b_{5}=185.3023 \\
b_{6}=0.2650\end{array}$ \\
\hline $\begin{array}{l}N=875 \\
r^{2}=0.440\end{array}$ & $\begin{array}{l}N=875 \\
r^{2}=0.563\end{array}$ & $\begin{array}{l}N=875 \\
r^{2}=0.572\end{array}$ \\
\hline
\end{tabular}


Table 3

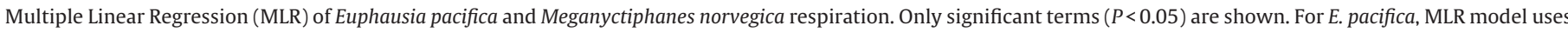

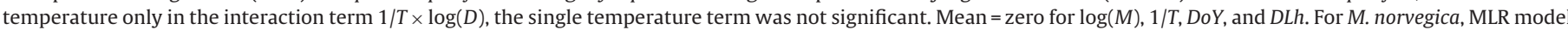
uses depth only in the interaction term $\log (D) \times \log (M)$, the single depth term was not significant.

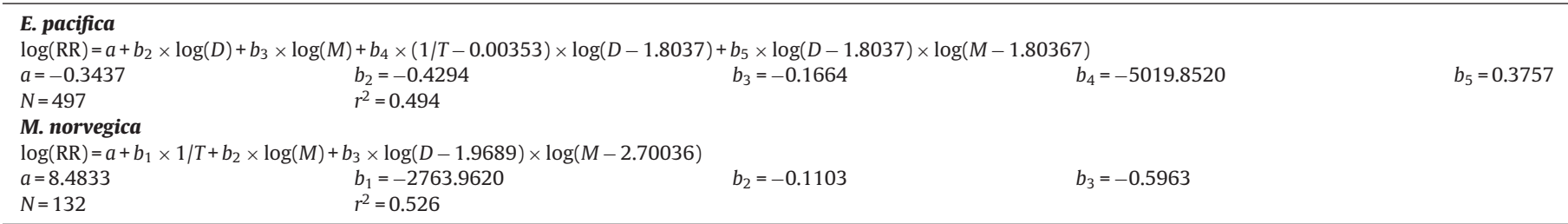
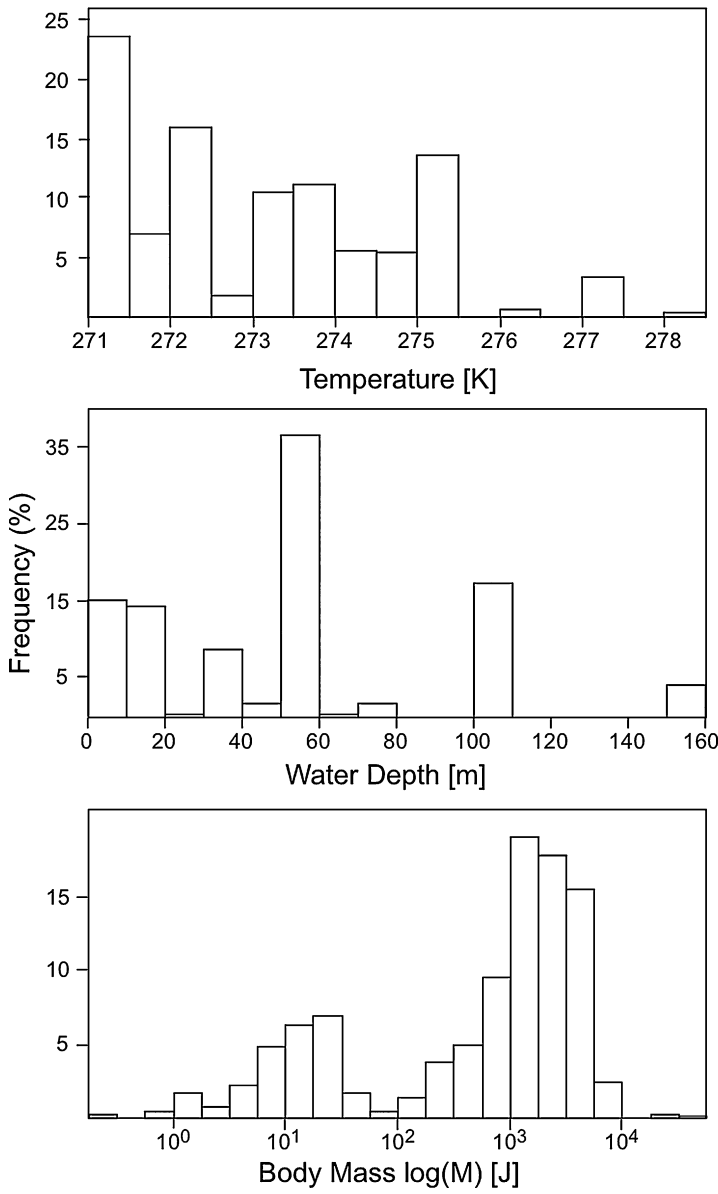

Fig. 7. Euphausia superba: Distribution of the 875 data sets used for model building with respect to water temperature (Kelvin), water depth (meters), and mean body mass (Joule).

\section{Discussion}

\subsection{General Euphausiid respiration model}

The ANN model confirms that geography (LAT) and seasons $(D L h)$ should be considered in a global Euphausiid respiration model, additionally to the main parameters presented by Ikeda (2012; biomass, depth and temperature). The ANN model also highlights a taxonomic influence on the respiration rates. The good model fit $\left(r^{2}=0.780\right)$ is confirmed by an acceptable residual variance, that is narrower than in a previous aquatic invertebrate respiration ANN in which Euphausiids represented only $3 \%$ of the data sets (Brey, 2010). The three taxonomic groups identified may, to some extent, relate to the geographical distribution of the corresponding genera. Meganyctiphanes and Thysanoessa are mainly present beyond $50^{\circ} \mathrm{N}$, while Nematoscelis are found around $40^{\circ}$ in

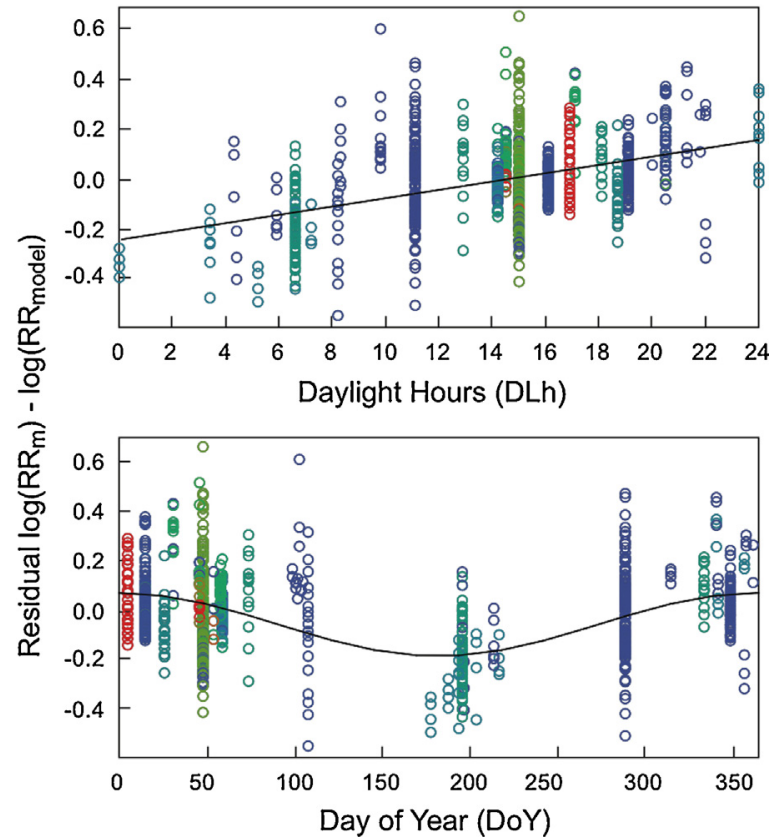

Fig. 8. Euphausia superba: Residuals of Multiple Linear Regression(MLR)(see Table 2 for model parameters) plotted versus Daylight hours (DLh) and Day of Year DoY. There is a significant linear relationship between residuals and $D L h\left(r^{2}=0.179\right.$ $P<0.001)$ and a significant sinusoidal relationship between residuals and $D o Y$ $\left(r^{2}=0.176, P<0.001\right)$. Colors indicate temperature at measurement ranging from $271 \mathrm{~K}$ (blue) to $278 \mathrm{~K}$ (red).

both hemispheres. Nyctiphanes and Thysanopoda species predominate around $30^{\circ}$ latitude in the data sources.

According to the present ANN model, Euphausiid specific respiration rate $R R$ decreases with higher latitude and decreasing $D L h$. The latitudinal influence is related to both body mass and temperature changes and follows the pattern observed by Ikeda (1985a) from net zooplankton community respiration. The DLh or photoperiod length correlates with high productivity events (spring bloom) at higher latitudes, which probably cause enhanced feeding activities and higher metabolic rates. However, the influence of DLh, LAT and genus should not be over-interpreted. We cannot be sure whether we see a truly generalizable pattern of respiration, or whether this pattern represents an empirical best fit of the data, forced by the uneven geographical and seasonal distribution of species and data sources. The only latitude at which almost all day lengths (light hours) occur throughout the year is at $60^{\circ} \mathrm{S}$, where measurements are available for only one species, E. superba.

\subsection{Seasonal respiration models for single Euphausiid species}

\subsubsection{Euphausia superba}

E. superba is the best and most extensively studied species both in terms of seasonal differences as well as geographically, rendering a large and comprehensive data set available for our GAM 

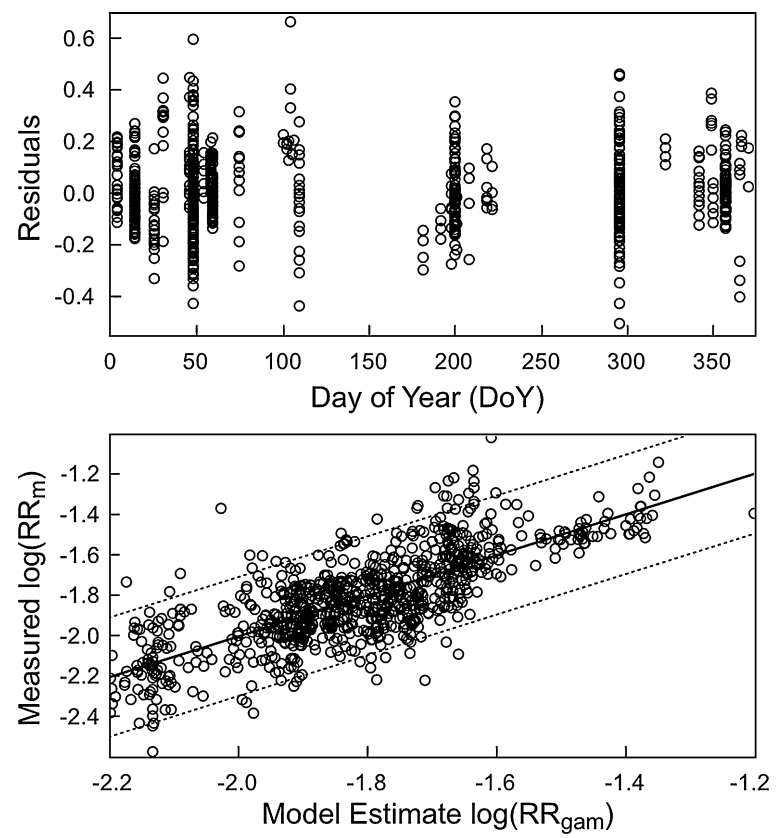

Fig. 9. Euphausia superba: Goodness of fit of the General Additive (GAM) model with $D o Y$ term (see Table 2 for model parameters). Plot of residuals versus $D o Y$ indicates no significant relationship $(P>0.1)$.

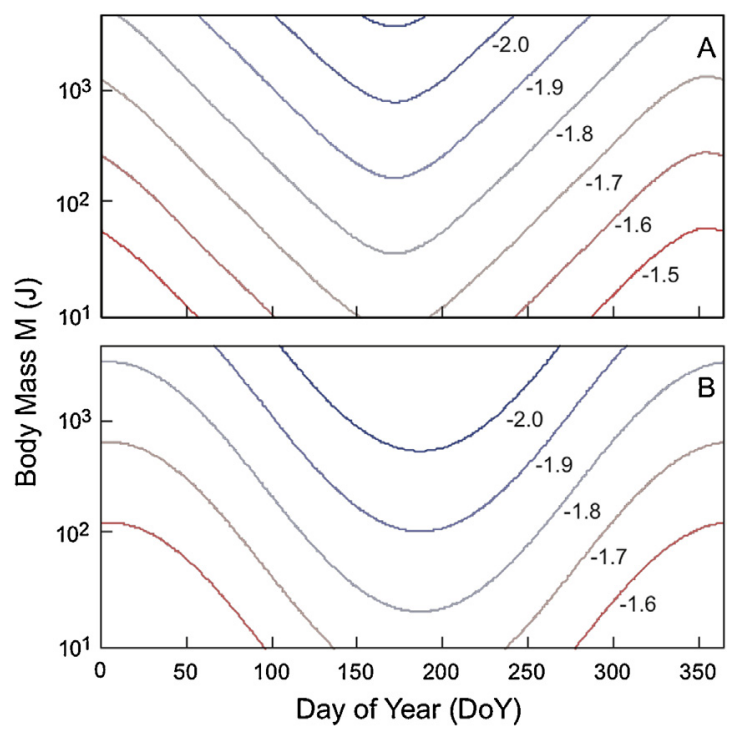

Fig. 10. Euphausia superba: Contour plot of $R R_{\text {gam }}$ predicted by the General Additive (GAM) models in the day of the year $D o Y$ versus bodymass $\log (M)$ space. Model with DLh term (A) and with $D o Y$ term (B), see Table 2 for model parameters. The relationship between $D o Y$ and $D L h$ used in (A) refers to $62^{\circ}$ S, i.e. the average latitude in all 875 data sets.

approach. The GAM indicates $D L h$ and $D o Y$ to be explanatory variables for $R R$ whereas it excluded $D$, presumably because sampling occurred almost exclusively within the upper $80 \mathrm{~m}$ of the water column and therewith in a narrow depth range. Including the $D L h$ term in the model revealed minimum metabolic activity in mid-June as opposed to a metabolic maximum at the end of December. A linear dependency of $R R$ on photoperiod ( $D L h)$ and the seasonal sinusoidal trend with DoY was found by Meyer (2011), who reviewed investigations on seasonal metabolic activity of krill in different regions of the Southern Ocean. Our study confirms those earlier findings, but on a broad base of data from different studies looking at animals

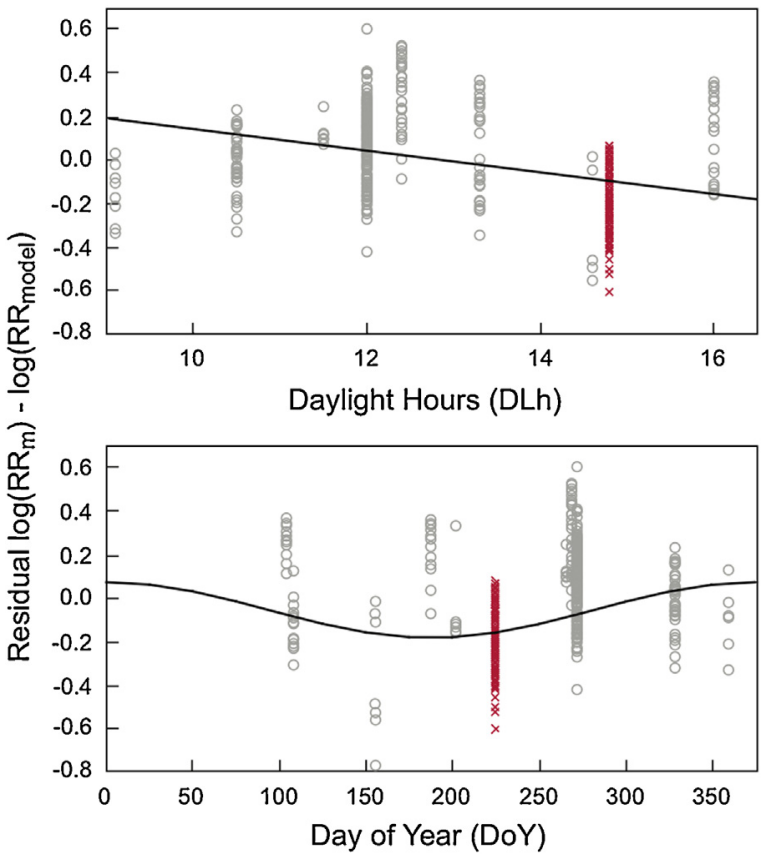

Fig. 11. Euphausia pacifica: Residuals of Multiple Linear Regression (MLR) (see Table 3 for model parameters) plotted versus Daylight Hours (DLh) and Day of Year DoY. The significant linear negative relationship with $D L h$ (slope $=-0.048$, $\left.r^{2}=0.137, P<0.001\right)$ as well as the sinusoidal relationship with $\operatorname{DoY}\left(r^{2}=0.099\right.$, $P<0.001$ ) becomes insignificant when the data of Paranjape (1967, cross symbols) are excluded.

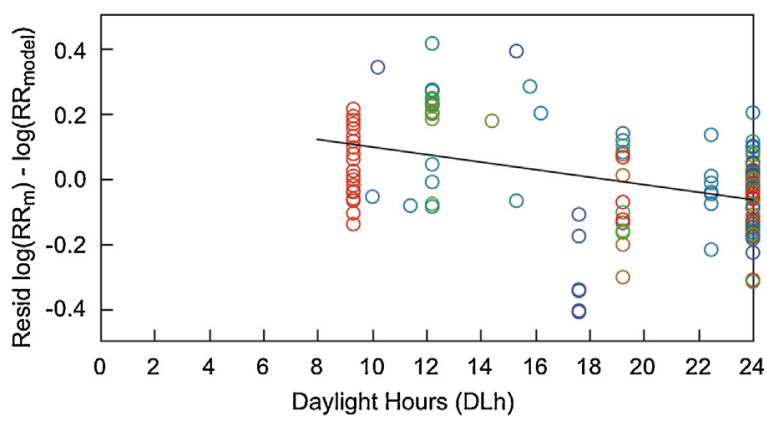

Fig. 12. Meganyctiphanes norvegica: Residuals of Multiple Linear Regression (MLR) (see Table 3 for model parameters) plotted versus Daylight Hours ( $D L h)$. Significant linear negative relationship with $D L h$ (slope $=-0.012, r^{2}=0.186, P<0.001$ ). Colors indicate temperature at measurement ranging from $273 \mathrm{~K}$ (blue) to $289 \mathrm{~K}$ (red).

from regions across the whole Antarctic Ocean. This pattern shows evidence for a general metabolic strategy in E. superba, which has been investigated from the molecular (Seear et al., 2009; Teschke et al., 2011) to the organism level (Atkinson et al., 2002; Teschke et al., 2007; Gaten et al., 2008; Pape et al., 2008; Brown et al., 2013). Although, the signaling cascade that links the photoperiod cue to the target response still remains unknown, the photoperiodic cycle clearly seems to act as a major Zeitgeber for the seasonal cycle of $R R$, suggesting that krill has evolved an endogenous time keeping system that perceives seasonal variations in photoperiod (Meyer, 2011). Teschke et al. (2011) identified an endogenous circadian timing system in Antarctic krill and found evidence for its link to metabolic key processes on a $24 \mathrm{~h}$ basis, which could also be involved in the control of seasonal events. Thus, the seasonal cycle of $R R$ in krill could be linked to an endogenous timing system, synchronized with the seasonal course of photoperiod in the environment. In a long-term experimental study lasting several years, 
Brown et al. (2013) maintained E. superba first under simulated natural photoperiod, before they exposed part of the group to complete darkness and variable food availability and temperature over several months. These experiments showed that E. superba maintained similar $R R$ patterns under constant darkness as under a simulated natural light regime. The authors suggested an endogenous rhythm of $R R$ that was naturally "imprinted" and sustained during the one-year experimental acclimatization period under the natural light cycle. The sinusoidal pattern shown by the GAM therefore represents an applicable tool for the investigation of deviations from the "internal clock" mechanism (Kawaguchi et al., 2007; Seear et al., 2009; Brown et al., 2011; Meyer, 2011; Teschke et al., 2011) by revealing conditions that cause divergence from the theoretical annual pattern of synchronized respiration.

\subsubsection{Euphausia pacifica and Meganyctiphanes norvegica}

Unfortunately much less data sets are available for $E$. pacifica and $M$. norvegica than for E. superba. These two species are widely distributed over the north Pacific and Atlantic (from 27.50 to $65.67^{\circ}$ $\mathrm{N}$ and 29.94 to $71.14^{\circ} \mathrm{N}$, respectively; Brinton et al., 2003, updated 2008), and the data sets are geographically wide spread, accordingly, making difficult to detect significant seasonal patterns. In $E$. pacifica, detection of $D o Y$ or DLh effects depended exclusively on the data set of Paranjape (1967), data which were treated as outlier also in earlier studies, as the reported $R R$ is conspicuously low (Ikeda et al., 2000). This is thought to reflect the permanent anoxic conditions in the deep waters of Saanich Inlet (Canada; Ikeda et al., 2000).

In M. norvegica, the available data indicate a negative correlation between the MLR residuals and DLh (Fig. 12), i.e. just the opposite of the relationship found in the Antarctic E. superba. However, our data base does neither represent the full range of $D L h$ nor the natural temperature range experienced by $M$. norvegica. There is some evidence for seasonal patterns in respiration of this species at lower latitudes (43 $\mathrm{N}$, Saborowski et al., 2002), but more data covering a wider range of the natural conditions experienced by $M$. norvegica are required for the establishment of a reliable model.

\section{Conclusion}

The present work confirms the effect of latitude, the day of the year of measurement, and the number of daylight hours on the respiration of Euphausiids. With this model we display the current global state of knowledge with respect to metabolic measurements available for some of the major Euphausiids, indicating where (degree of latitude) and when (time of the year) data are available or missing. Many existing data gaps with respect to both, degree of latitude and timing, call for better coverage to improve future modeling attempts. The highest data coverage for the GAM model was available for the Antarctic krill E. superba, which helped to simulate and put numbers to the strong seasonal metabolic adjustments observed in this species.

\section{Acknowledgements}

This study is based on the careful respiration measurements of many euphausiid and zooplankton experts of the world. N. Tremblay had a doctoral scholarship from the Fonds de recherche sur la Nature et les Technologies du Québec (Canada).

\section{Appendix A. Supplementary data}

Supplementary data associated with this article can be found, in the online version, at http://dx.doi.org/10.1016/j.ecolmodel. 2014.07.031.

\section{References}

Atkinson, A., Meyer, B., Stübing, D., Hagen, W., Schmidt, K., Bathmann, U., 2002 Feeding and energy budgets of Antarctic krill Euphausia superba at the onset of winter-II. Juveniles and adults. Limnol. Oceanogr. 47, 953-966.

Barnett, V., Lewis, T., 1994. Outliers in Statistical Data, 3rd ed. John Wiley \& Sons, Inc.

Boucher, M.-A., Laliberté, J.-P., Anctil, F., 2010. An experiment on the evolution of an ensemble of neural networks for streamflow forecasting. Hydrol. Earth Syst. Sci. $14,603-612$.

Brey, T., 2010. An empirical model for estimating aquatic invertebrate respiration. Methods Ecol. Evol. 1, 92-101

Brey, T., 2012. A multi-parameter artificial neural network model to estimate macrobenthic invertebrate productivity and production. Limnol. Oceanogr.: Methods 10, 581-589.

Brinton, E., Ohman, M.D., Townsend, A.W., 2003. Euphausiids of the World Ocean, CD-ROM. ETI, BioInformatics, Amsterdam, The Netherlands, updated 2008.

Brown, J.H., Gillooly, J.F., Allen, A.P., Savage, V.M., West, G.B., 2004. Toward a metabolic theory of ecology. Ecology 85, 1771-1789.

Brown, M., Kawaguchi, S., King, R., Virtue, P., Nicol, S., 2011. Flexible adaptation of the seasonal krill maturity cycle in the laboratory. J. Plankton Res. 33, $821-826$

Brown, M., Kawaguchi, S., Candy, S., Yoshida, T., Virtue, P., Nicol, S., 2013. Long-term effect of photoperiod, temperature and feeding regimes on the respiration rates of Antarctic krill (Euphausia superba). Open J. Mar. Sci. 03, 40-51.

Draper, N.R., Smith, H., 1998. Applied Regression Analysis. Wiley-Interscience.

Enright, J.T., 1977. Diurnal vertical migration: adaptive significance and timing. Part 1. Selective advantage: a metabolic model. Limnol. Oceanogr. 22, 856-872.

Gaten, E., Tarling, G., Dowse, H., Kyriacou, C., Rosato, E., 2008. Is vertical migration in Antarctic krill (Euphausia superba) influenced by an underlying circadian rhythm? J. Genet. 87, 473-483.

Hagan, M.T., Demuth, H.B., Beale, M.H., 1996. Neural Network Design. PWS Publishing.

Haraldsson, M., Siegel, V., 2014. Seasonal distribution and life history of Thysanoessa macrura (Euphausiacea, Crustacea) in high latitude waters of the Lazarev Sea, Antarctica. Mar. Ecol. Prog. Ser. 495, 105-118.

Hastie, T., Tibshirani, R., 1990. Generalized Additive Models. Chapman \& Hall.

Ikeda, T., 1985a. Metabolic rates of epipelagic marine zooplankton as a function of body mass and temperature. Mar. Biol. 85, 1-11.

Ikeda, T., 2012. Respiration and ammonia excretion of Euphausiid crustaceans: synthesis toward a global-bathymetric model. Mar. Biol. 160, 251-262.

Ikeda, T., Torres, J., Hernández-León, S., Geiger, S., 2000. Metabolism. In: Harris, R. Wiebe, P., Lenz, J., Skjoldal, H., Huntley, M. (Eds.), ICES Zooplankton Methodology Manual. Academic Press, pp. 455-532.

Kawaguchi, S., Yoshida, T., Finley, L., Cramp, P., Nicol, S., 2007. The krill maturity cycle: a conceptual model of the seasonal cycle in Antarctic krill. Polar Biol. 30 689-698

Meyer, B., 2011. The overwintering of Antarctic krill, Euphausia superba, from an ecophysiological perspective. Polar Biol. 35, 15-37.

Pape, C., Teschke, M., Meyer, B., 2008. Melatonin and its possible role in mediating seasonal metabolic changes of Antarctic krill, Euphausia superba. Comp. Biochem. Physiol. A: Mol. Integr. Physiol. 149, 426-434.

Paranjape, M.A., 1967. Molting and respiration of Euphausiids. J. Fish. Board Can. 24 $1229-1240$

Prokhorov, A.V., 2001. Hotelling- ${ }^{2}$-distribution. In: Hazewinkel, M. (Ed.), Encyclopedia of Mathematics. Springer.

Saborowski, R., Bröhl, S., Tarling, G., Buchholz, F., 2002. Metabolic properties of Northern krill, Meganyctiphanes norvegica, from different climatic zones. I. Respiration and excretion. Mar. Biol. 140, 547-556.

Sato, M., Dower, J., Kunze, E., Dewey, R., 2013. Second-order seasonal variability in diel vertical migration timing of Euphausiids in a coastal inlet. Mar. Ecol. Prog. Ser. 480, 39-56.

Schmidt-Nielsen, K., 1984. Scaling - Why is Animal Size so Important? Cambridge University Press.

Seear, P., Tarling, G.A., Teschke, M., Meyer, B., Thorne, M.A.S., Clark, M.S., Gaten E., Rosato, E., 2009. Effects of simulated light regimes on gene expression in Antarctic krill (Euphausia superba Dana). J. Exp. Mar. Biol. Ecol. 381, 57-64.

Seibel, B., Drazen, J., 2007. The rate of metabolism in marine animals: environmental constraints, ecological demands and energetic opportunities. Philos. Trans. R. Soc. B: Biol. Sci. 362, 2061

Taki, K., 2008. Vertical distribution and diel migration of Euphausiids from Oyashio Current to Kuroshio area off northeastern Japan. Plankton Benthos Res. 3, 27-35

Teschke, M., Kawaguchi, S., Meyer, B., 2007. Simulated light regimes affect feeding and metabolism of Antarctic krill, Euphausia superba. Limnol. Oceanogr. 52, 1046-1054

Teschke, M., Wendt, S., Kawaguchi, S., Kramer, A., Meyer, B., 2011. A circadian clock in Antarctic krill: an endogenous timing system governs metabolic output rhythms in the euphausid species Euphausia superba. PLoS ONE 6, e26090.

Tremblay, N., Gómez-Gutiérrez, J., Zenteno-Savín, T., Robinson, C.J., Sánchez-Velasco L., 2010. Role of oxidative stress in seasonal and daily vertical migration of three krill species in the Gulf of California. Limnol. Oceanogr. 55, 2570-2584.

Tremblay, N., Werner, T., Huenerlage, K., Buchholz, F., Abele, D., Meyer, B., Brey T., 2014. Euphausiid Respiration Model Revamped, Link to Model Results., http://dx.doi.org/10.1594/PANGAEA.831413.

Werner, T., Buchholz, F., 2013. Diel vertical migration behaviour in Euphausiids of the northern Benguela current: seasonal adaptations to food 
availability and strong gradients of temperature and oxygen. J. Plankton Res. 35, 792-812.

\section{Data sources}

Agersted, M.D., Nielsen, T.G., Munk, P., Vismann, B., Arendt, K.E., 2011. The functional biology and trophic role of krill (Thysanoessa raschii) in a Greenlandic fjord. Mar. Biol. 158, 1387-1402.

Antezana, T., 2002. Adaptive behaviour of Euphausia mucronata in relation to the oxygen minimum layer of the Humboldt Current. In: Färber-Lorda, J. (Ed.), Oceanography of the Eastern Pacific. CICESE, pp. 29-40.

Båmstedt, U., 1979. Seasonal variation in the respiratory rate and ETS activity of deep-water zooplankton from the Swedish west coast. In: Naylor, E., Hartnoll, R.G. (Eds.), Cyclic Phenomena in Marine Plants and Animals. Pergamon Press.

Childress, J., 1975. The respiratory rates of midwater crustaceans as a function of depth of occurrence and relation to the oxygen minimum layer off southern California. Comp. Biochem. Physiol. A: Physiol. 50, 787-799.

Conover, R.J., Corner, E., 1968. Respiration and nitrogen excretion by some marine zooplankton in relation to their life cycles. J. Mar. Biol. Assoc. U. K. 48, 49-75.

Cowles, D.L., Childress, J.J., Wells, M.E., 1991. Metabolic rates of midwater crustaceans as a function of depth of occurrence off the Hawaiian Islands: food availability as a selective factor? Mar. Biol. 110, 75-83.

Davenport, J., Trueman, E.R., 1985. Oxygen uptake and buoyancy in zooplanktonic organisms from the tropical eastern Atlantic. Comp. Biochem. Physiol. A: Physiol. $81,857-863$

Donnelly, J., Torres, J., 1988. Oxygen consumption of midwater fishes and crustaceans from the eastern Gulf of Mexico. Mar. Biol. 97, 483-494.

Harding, G.C.H., 1977. Surface area of the Euphausiid Thysanöessa raschii and its relation to body length, weight, and respiration. J. Fish. Board Can. 34, 225-231.

Hirche, H.J., 1983. Excretion and respiration of the Antarctic krill Euphausia superba. Polar Biol. 1, 205-209.

Hirche, H.J., 1984. Temperature and metabolism of plankton - I. Respiration of Antarctic zooplankton at different temperatures with a comparison of Antarctic and Nordic krill. Comp. Biochem. Physiol. A: Physiol. 77, 361-368.

Ikeda, T., 1974. Nutritional ecology of marine zooplankton. Mem. Fac. Fish. Hokkaido Univ. 22, 1-97.

Ikeda, T., 1977. The effect of laboratory conditions on the extrapolation of experimental measurements to the ecology of marine zooplankton. IV. Changes in respiration and excretion rates of boreal zooplankton species maintained under fed and starved conditions. Mar. Biol. 41, 241-252.

Ikeda, T., 1981. Metabolic activity of larval stages of Antarctic krill. Antarct. J. U. S. $16,161-162$.

Ikeda, T., 1985b. Metabolic rate and elemental composition ( $\mathrm{C}$ and $\mathrm{N}$ ) of embryos and non-feeding early larval stages of antarctic krill (Euphausia superba Dana). J. Exp. Mar. Biol. Ecol. 90, 119-127.

Ikeda, T., 1988. Metabolism and chemical composition of crustaceans from the Antarctic mesopelagic zone. Deep-Sea Res. 35, 1991-2002.

Ikeda, T., Bruce, B., 1986. Metabolic activity and elemental composition of krill and other zooplankton from Prydz Bay, Antarctica, during early summer (November-December). Mar. Biol. 92, 545-555.

Ikeda, T., Kirkwood, R., 1989. Metabolism and body composition of two Euphausiids (Euphausia superba and E. crystallorophias) collected from under the pack-ice off Enderby Land, Antarctica. Mar. Biol. 100, 301-308.

Ikeda, T., McKinnon, A.D., 2012. Metabolism and chemical composition of zooplankton and hyperbenthos from the Great Barrier Reef waters, North Queensland, Australia. Plankton Benthos Res. 7, 8-19.
Ikeda, T., Mitchell, A.W., 1982. Oxygen uptake, ammonia excretion and phosphate excretion by krill and other Antarctic zooplankton in relation to their body size and chemical composition. Mar. Biol. 71, 283-298.

Ikeda, T., Skjoldal, H.R., 1989. Metabolism and elemental composition of zooplankton from the Barents Sea during early Arctic summer. Mar. Biol. 100, 173-183.

Ishii, H., Omori, M., Maeda, M., Watanabe, Y., 1987. Metabolic rates and elemental composition of the Antarctic krill, Euphausia superba Dana. Polar Biol. 7, 379-382.

Ivleva, I., 1980. The dependence of crustacean respiration rate on body-mass and habitat temperature. Int. Rev. Gesamten Hydrobiol. 65, 1-47.

Kils, U., 1979. Performance of Antarctic krill Euphausia superba, at different levels of oxygen saturation. Meeresforschung 27, 35-48.

Kim, H.S., Yamaguchi, A., Ikeda, T., 2010. Metabolism and elemental composition of the Euphausiids Euphausia pacifica and Thysanoessa inspinata during the phytoplankton bloom season in the Oyashio region, western subarctic Pacific Ocean. Deep-Sea Res. II 57, 1733-1741.

Mayzaud, P., 1973. Respiration and nitrogen excretion of zooplankton. II. Studies of the metabolic characteristics of starved animals. Mar. Biol. 21, 19-28.

Meyer, B., Atkinson, A., Stübing, D., Hagen, W., Bathmann, U., 2002. Feeding and energy budgets of Antarctic krill Euphausia superba at the onset of winter in the Lazarev Sea (juveniles, adults furcilia III larvae). Limnol. Oceanogr. 47, 943-952.

Meyer, B., Fuentes, V., Guerra, C., Schmidt, K., Atkinson, A., Spahic, S., Cisewski, B., Freier, U., Olariaga, A., Bathmann, U., 2009. Physiology, growth and development of larval krill Euphausia superba in autumn and winter in the Lazarev Sea, Antarctica. Limnol. Oceanogr. 54, 1595-1614.

Pearcy, W.G., Theilacker, G.H., Lasker, R., 1969. Oxygen consumption of Euphausia pacifica: the lack of a diel rhythm or light-dark effect, with a comparison of experimental techniques. Limnol. Oceanogr. 14, 219-223.

Rakusa-Suszczewhki, S., Opalinski, K.W., 1978. Oxygen consumption in Euphausia superba. Pol. Arch. Hydrobiol. 25, 633-641.

Ross, R., 1982. Energetics of Euphausia pacifica. I. Effects of body carbon and nitrogen and temperature on measured and predicted production. Mar. Biol. 68, 1-13.

Sameoto, D.D., 1976. Respiration rates, energy budgets, and molting frequencies of three species of Euphausiids found in the Gulf of St. Lawrence. J. Fish. Board Can. 33, 2568-2576.

Segawa, S., Kato, M., Murano, M., 1982. Respiration and ammonia excretion rates of the Antarctic krill, Euphausia superba Dana. Trans. Tokyo Univ. Fish. 5, 177-187.

Small, L., Hebard, J., 1967. Respiration of a vertically migrating marine crustacean Euphausia pacifica Hansen. Limnol. Oceanogr. 12, 272-280.

Torres, J., Childress, J., 1983. Relationship of oxygen consumption to swimming speed in Euphausia pacifica. Mar. Biol. 74, 79-86.

Torres, J.J., Aarset, A.V., Donnelly, J., Hopkins, T.L., Lancraft, T.M., Ainley, D.G., 1994 Metabolism of Antarctic micronektonic Crustacea as a function of depth of occurrence and season. Mar. Ecol. Prog. Ser. 113, 1-15.

Tremblay, N., Zenteno-Savín, T., Gómez-Gutiérrez, J., Maeda-Martínez, A.N., 2011. Migrating to the oxygen minimum layer: Euphausiids. In: Abele, D., ZentenoSavín, T., Vázquez-Medina, J.P. (Eds.), Oxidative Stress in Aquatic Ecosystems. John Wiley \& Sons, Ltd., pp. 89-98.

Vidal, J., Whitledge, T.E., 1982. Rates of metabolism of planktonic crustaceans as related to body weight and temperature of habitat. J. Plankton Res. 4, 77-84.

Voss, J., (Bachelor thesis) 1982. Respiration von Euphausia superba Dana und Meganyctipanes norvegica (M. Sars) in Abhängigkeit von Größe und Temperatur. Universität Kiel.

Werner, T., Huenerlage, K., Verheye, H., Buchholz, F., 2012. Thermal constraints on the respiration and excretion rates of krill, Euphausia hanseni and Nematoscelis megalops, in the northern Benguela upwelling system off Namibia. Afr. J. Mar. Sci. 34, 391-399. 